\title{
Second Reply to Letter to the Editor re: "Clinical utility of the Prostate Health Index (phi) for biopsy decision management in a large group urology practice setting"
}

\author{
Jay White ${ }^{1,4} \cdot$ Ronald F. Tutrone ${ }^{2} \cdot$ Mark A. Reynolds $^{3}$ \\ Received: 20 June 2019 / Accepted: 4 July 2019 / Published online: 28 August 2019 \\ (c) The Author(s) 2019. This article is published with open access
}

We wish to further respond to the letter of Ehdaie and Carlsson [1], wherein the authors questioned "the lack of any mentioning to the risk of missed high-grade disease" in our originally published article [2]. As stated in the article, our study was designed to address two objectives: (1) to identify the impact of phi on decision to biopsy in a community practice setting; and (2) to assess the biopsy yield of cancer with and without the use of phi. As reported in our study, we observed a $23.9 \%$ reduction in biopsy procedures performed between the Prospective (with phi) and Historical (without phi) cohorts, along with a modest reduction in the percentage of low-grade (GS 6) cancers detected $(9.9 \%$ versus $18.4 \%$ ). However, as reiterated in our first Reply [3], this study was not sufficiently powered to address the question of high-grade vs. low-grade cancers. Simply put, the relatively low numbers of high-grade cancers recorded in our study would not have supported a robust statistical comparison. To illustrate that point, an analysis by Gleason score (GS) is presented below in Table 1.

As shown in the table, the Prospective cohort showed a modest reduction in percentages of GS 6 and GS $(3+4)$ cancers detected (differences of $8.5 \%$ and $5.5 \%$, respectively), whereas the percentages of GS $(4+3)$ cancers were nearly equivalent. The GS $>7$ cancers showed overlapping confidence intervals, as one might expect due to the relatively low and variable numbers of high-grade cancers recorded among the four participating sites in our study.

\footnotetext{
Jay White

jayswhite@yahoo.com

Carolina Urology Partners, Huntersville, NC, USA

2 Chesapeake Urology Associates, Towson, MD, USA

3 Beckman Coulter, Carlsbad, CA, USA

4 Present address: The Medical Affairs Company, Kennesaw, GA, USA
}

Similarly, when pooling the unfavorable intermediate-risk and high-risk patients (GS $(4+3)$ and GS $>7$ ), we also find overlapping confidence intervals. Furthermore, when considering just the numbers of positive cancers recorded, we observed an enrichment of high-grade cancers in the Prospective cohort. When utilizing phi, our detection rate of clinically significant prostate cancer (GS $(4+3)$ and $>7)$ was $24.2 \%$ (26/107) versus $18.3 \%$ (46/251) for the Historical cohort. These comparisons are offered in the interest of full transparency. Again, the small number of patients with high-grade cancers precludes any formative conclusions.

Nonetheless, the question of high-grade cancer requires further comment. The population of men enrolled in our study had a non-suspicious DRE and a recent total PSA 4-10 ng/mL. Recent guidelines published by the American Urological Association recommend active surveillance be offered to such men with organ-confined prostate cancer, a Gleason Score of $\leq(3+4)$ and tPSA $<10 \mathrm{ng} / \mathrm{mL}$ [4]. Accordingly, our data do not support the assertion offered by Ehdaie and Carlsson that a urologist's decision to defer biopsy, when guided by clinical judgment along with the phi result, presents a significant risk of missing high-grade disease. Furthermore, as reported in our study, patients not biopsied following their initial assessment are expected to be monitored more closely or by additional methodologies. This observation, along with the most recent NCCN guidelines recommending repeat assessment of PSA and DRE within 6-12 months, supports our conclusion that a biopsy was safely deferred in such men.

Finally, we wish to acknowledge that no biomarker test for prostate cancer can fully exclude the risk of missing high-grade disease, and that even the best such tests currently available offer relatively equivalent performance. For example, a recent meta-analysis of 28 studies including 16,762 patients comparing phi to 4 KScore ${ }^{\oplus}$ concluded that both markers provided comparable diagnostic accuracy in detecting overall and high-grade PCa [5]. 
Table 1 Gleason score in historical and prospective cohorts

\begin{tabular}{|c|c|c|c|c|c|}
\hline \multirow[b]{2}{*}{ GS } & \multicolumn{2}{|c|}{ Historical $(n=683)$} & \multicolumn{2}{|c|}{ Prospective $(n=506)$} & \multirow[b]{2}{*}{$p$-value } \\
\hline & $n$ & Percent $(95 \% \mathrm{Cl})^{\mathrm{a}}$ & $n$ & Percent $(95 \% \mathrm{Cl})^{\mathrm{a}}$ & \\
\hline 6 & 126 & $18.4(15.6,21.6)$ & 50 & $9.9(7.3,12.5)$ & $<0.001$ \\
\hline $3+4$ & 79 & $11.6(9.3,14.2)$ & 31 & $6.1(4.0,8.2)$ & 0.001 \\
\hline $4+3$ & 24 & $3.5(2.3,5.2)$ & 19 & $3.8(2.1,5.4)$ & 0.807 \\
\hline$>7$ & 22 & $3.2(2.0,4.8)$ & 7 & $1.4(0.4,2.4)$ & $<0.001$ \\
\hline $6+(3+4)$ & 205 & $30.0(26.6,33.6)$ & 81 & $16.0(12.8,19.2)$ & 0.245 \\
\hline$(4+3)+>7$ & 46 & $6.7(4.9,8.9)$ & 26 & $5.1(3.2,7.1)$ & 0.031 \\
\hline
\end{tabular}

${ }^{a}$ The Wald approach was used to calculate confidence intervals using Proc Freq of SAS, Version 9.4M3 of the SAS System ${ }^{\odot} 2015$ (SAS Institute Inc., Cary, NC, USA). All comparisons conducted with $\alpha=0.05 ; p$-value $\mathrm{H}_{\mathrm{A}}$ : Diff $\neq 0$

\section{Compliance with ethical standards}

Conflict of interest MAR is an employee of Beckman Coulter. The remaining authors declare that they have no conflict of interest.

Publisher's note: Springer Nature remains neutral with regard to jurisdictional claims in published maps and institutional affiliations.

Open Access This article is licensed under a Creative Commons Attribution 4.0 International License, which permits use, sharing, adaptation, distribution and reproduction in any medium or format, as long as you give appropriate credit to the original author(s) and the source, provide a link to the Creative Commons license, and indicate if changes were made. The images or other third party material in this article are included in the article's Creative Commons license, unless indicated otherwise in a credit line to the material. If material is not included in the article's Creative Commons license and your intended use is not permitted by statutory regulation or exceeds the permitted use, you will need to obtain permission directly from the copyright holder. To view a copy of this license, visit http://creativecommons. org/licenses/by/4.0/.

\section{References}

1. Ehdaie B, Carlsson S. Reply to 'Clinical utility of the Prostate Health Index (phi) for biopsy decision management in a large group urology practice setting'. Prostate Cancer Prostatic Dis. 2018;21:446-7.

2. White J, Shenoy BV, Tutrone RF, Karsh LI, Saltzstein DR, Harmon WJ, et al. Clinical utility of the Prostate Health Index (phi) for biopsy decision management in a large group urology practice setting. Prostate Cancer Prostatic Dis. 2018;21:78-84.

3. White J, Tutrone RF. Reply to Letter to the Editor re: 'Clinical utility of the Prostate Health Index (phi) for biopsy decision management in a large group urology practice setting'. Prostate Cancer Prostatic Dis. 2018;21:604.

4. Sanda MG, Cadeddu JA, Kirkby E, Chen RC, Crispino T, Fontanarosa J, et al. Clinically Localized Prostate Cancer: AUA/ASTRO/ SUO Guideline. Part I: Risk Stratification, Shared Decision Making, and Care Options. J Urol 2018;199:683-90.

5. Russo GI, Regis F, Castelli T, Favilla V, Privitera S, Giardina R, et al. A systematic review and meta-analysis of the diagnostic accuracy of prostate health index and 4-Kallikrein Panel Score in predicting overall and high-grade prostate cancer. Clin Genitourin Cancer. 2017;15:429-39. 